\title{
Latent learning and the partial reinforcement effect
}

\author{
ELVIS C. JONES \\ TEXAS CHRISTIAN UNIVERSITY
}

Satiated $S$ s were exposed to a distinctive food in a runway goal box on a consistent or intermittent basis. Half of the Ss in each group had prior experience with the food and the other half were naive. Tested under deprivation, a partial reinforcement effect was obtained, the effect being stronger for the Ss which were experienced with the food.

MacCorquodale \& Meehl (1954) summarize a number of studies which provide evidence that animals, shown the location of food while satiated, will demonstrate learning when later deprived. One aim of the present experiment was to determine if a partial reinforcement effect (PRE) could be established in such a latent lea rning situation. A second aim was to determine whether an obtained PRE could be attributed to factors other than simple stimulus novelty or satiation (Glanzer, 1958). This is a question of relevance to many PRE and latent learning experiments.

\section{Method}

The Ss were 20 female Sprague-Dawley rats, 110 days old at the start of the experiment. All Ss were raised on Purina Laboratory Chow. The Ss were trained in a straight runway, 48 in. long, 4-1/2 in. wide, and 6 in. high, excluding the goal box. The goal box was 10 in. $x 4-1 / 2$ in. $x 6$ in. In the goal box was a copper food cup, 2 in. in diameter and $1 / 2$ in. deep.

The Ss were divided into four equal groups on the basis of weight. Two groups were fed only Noyes Precision Food Pellets for $48 \mathrm{hr}$. These constituted the experienced groups. Noyes Pellets are $4.0 \mathrm{~mm} \mathrm{x}$ $3.3 \mathrm{~mm}$ and weigh $45 \mathrm{mg}$. The other two groups spent the same period on their regular diet of Purina Chow. These were the naive groups. Next, all Ss were given three training trials in the runway every three days for a total of 24 trials. The intertrial interval was 15 min. For one group of experienced, and one group of naive Ss, five Noyes Pellets were present in the food cup on every trial. These were the consistent reinforcement (CR) groups. For the other two groups, the pellets were present on only $50 \%$ of the trials, on a random basis. These were the partial reinforcement (PR) groups. All Ss were satiated on food and water throughout training.

The goal box door was never opened during the training period. On each training trial the $S$ was placed directly into the goal box facing the food cup. Thirty sec. later, the $S$ was removed to the start of the runway and allowed $2-1 / 2 \mathrm{~min}$. to freely explore all of the apparatus except the goal box. Prior to each unreinforced trial the goal box and food cup were washed and dried. The entire apparatus was cleaned after every fourth use.

Following the last day of training, each $\mathrm{S}$ was deprived of food for $23 \mathrm{hr}$, and given 12 extinction trials each day for two days. The intertrial interval was $5 \mathrm{~min}$., except that a $25 \mathrm{~min}$. period intervened between trial 6 and 7, and between 18 and 19. During extinction the pellets were never present in the food cup. The Ss were placed at the start of the runway and the goal box door was closed behind them as soon as they entered the goal box. Thirty sec. later the Ss were removed to await the next trial in cages supplied with water, but no food.

\section{Results and Discussion}

Trend analysis, based on reciprocal latencies averaged over blocks of three trials, revealed a number of significant outcomes. An arbitrary decision had been made to run 24 extinction trials. The nature of the groups by trials interaction was such as to preclude any meaningful comparisons between scores totaled over all trials.

As can be seen in Fig. 1, a PRE was obtained (percent reinforcement by trials, $F=2.326, d f=7 / 112, p<.05$ ), despite the fact that relatively few acquisition trials were given and the $C R$ group received twice as many reinforcements as the PR group.

Experience with the reinforcer made a difference in resistance to extinction (experience by trials, $F=11.852, d f=7 / 112, p<.001)$. Both experienced groups performed better than their naive counterparts.

The percent reinforcement by experience by trials interaction was also significant $(F=15.659, \mathrm{df}=7 / 112$,

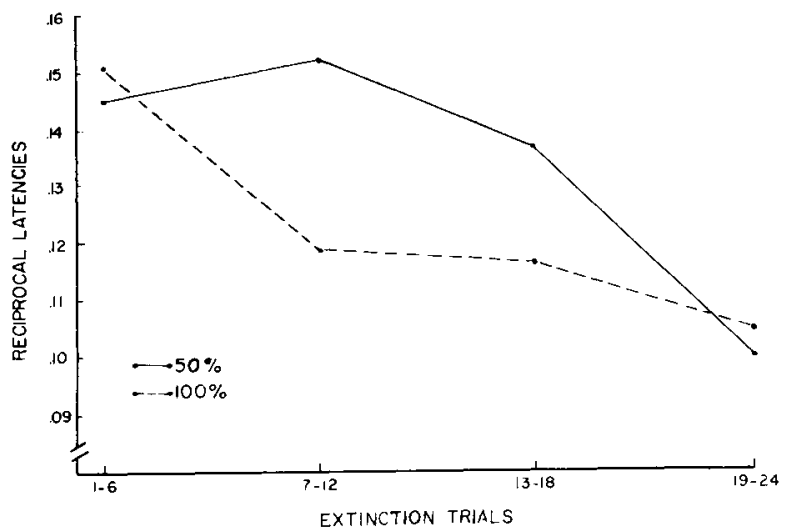

Fig. 1. Extinction performance following partial and consistent reinforcement. 


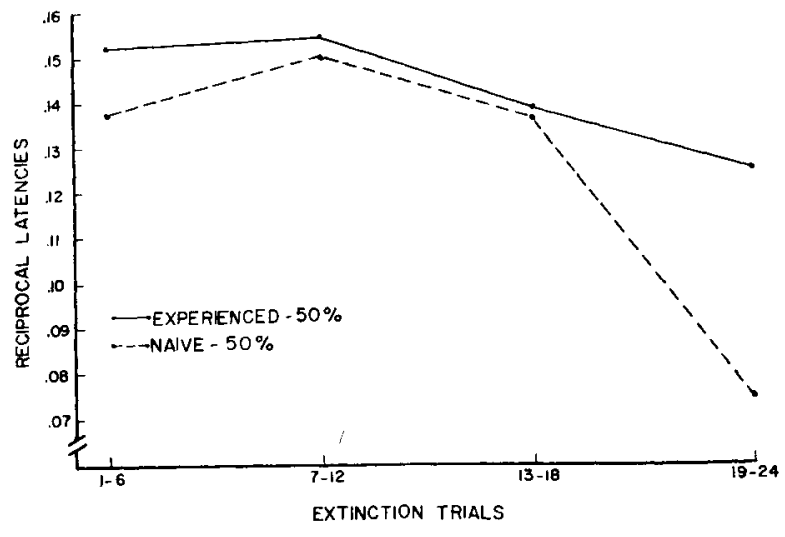

Fig. 2. Extinction performance of experienced and naive Ss following partial reinforcement.

$p<.001)$. A strong PRE was obtained not only with experienced $\mathrm{Ss}$, but also with naive $\mathrm{Ss}$, suggesting that PRE can be based upon a novelty factor. However, as can be seen in Fig. 2, the performance of the experienced PR group surpassed that of the naive PR group, the differences reaching a maximum at the end of extinction.

Noyes Pellets differ in size, shape, texture, and brightness from the Purina Chow on which the Ss had been raised. Therefore, Noyes Pellets should have no secondary reinforcement value based on their food properties, except for the experienced Ss. However, after the experiment was underway, it occurred to the $E$ that laboratory rats encounter only flooring material, feces, and food in their cages. Since Noyes Pellets are probably more similar to food than to flooring material or feces, then even for the naive Ss the pellets probably do have some secondary reinforcement value. Nevertheless, the pellets should be more reinforcing for the experienced Ss since they had actually consumed some.

In many latent learning experiments it is unclear to what extent the Ss' performance is determined by stimulus novelty and stimulus satiation. When the PRE is involved, there is the possibility that for the CR Ss, the reinforcing object undergoes stimulus satiation through repeated exposure. The PR Ss, however, are exposed to a variable stimulus situation and the reinforcing object tends to retain its novelty longer. If stimulus novelty and satiation are the critical variables, then the experienced Ss in the present experiment should have extinguished more rapidly than the naive Ss. They were, however, more resistant to extinction. This indicates that the PRE cannot be accounted for purely on the basis of stimulus novelty or satiation.

The $\mathrm{E}$ is disinclined to accept an expectancy explanation of PRE. However, if these results represent a stable phenomenon, then fractional anticipatory goal responses and frustration responses seem no better suited to handle the problem. For example, why should a satiated rat be frustrated when he fails to see pellets which he does not eat anyway? If mediating responses continue to be inferred, rather than observed, they should be treated as theoretical constructs, no more "real" than expectancies.

\section{References}

Glanzer, M. Curiosity, exploratory drive, and stimulus satiation. Psychol. Bull., 1958, 55, 302-315.

MacCorquodale, K., \& Meehl, P. E. Edward C. Tolman. In W. K. Estes, S. Koch, K. MacCorquodale, P. E. Meehl, C. G. Mueller, W. N. Schoenfeld and W. S. Verplanck (Eds.), Modern learning theory. New York: Appleton-Century-Crofts, 1954. 